(2) Open Access Full Text Article

REVIEW

\title{
Intravitreal anti-VEGF injections for treating wet age-related macular degeneration: a systematic review and meta-analysis
}

This article was published in the following Dove Press journal:

Drug Design, Development and Therapy

28 September 2015

Number of times this article has been viewed

\author{
Jun $\mathrm{Ba}^{1,2, *}$ \\ Run-Sheng Peng ${ }^{2, *}$ \\ Ding $X u^{\prime}$ \\ Yan-Hong Li' \\ Hui Shi ${ }^{1,3}$ \\ Qianyi Wang' \\ Jing Yu'
}

'Department of Ophthalmology, Shanghai Tenth People's Hospital Affiliated with Tongji University, ${ }^{2}$ Department of Cardiac Surgery, Institute of Cardiovascular Diseases of Fudan University, Affiliated Zhongshan Hospital of Fudan University, Shanghai, People's Republic of China; ${ }^{3}$ Department of First Clinical Medical College, Nanjing Medical University, Nanjing, Jiangsu, People's Republic of China

*Co-first authors of this work
Correspondence: jing Yu

Department of Ophthalmology, Shanghai

Tenth People's Hospital Affiliated

with Tongji University, 30 I Middle

Yanchang Road, Shanghai 200072,

People's Republic of China

Tel +86 2l 6630 I362

Email dryujing@aliyun.com
Aims: Age-related macular degeneration (AMD) is the main cause of blindness. Anti-vascular endothelial growth factor is used to prevent further neovascularization due to wet AMD. The purpose of this systematic review was to investigate the effect and protocol of anti-vascular endothelial growth factor treatment on wet AMD.

Methods: A comprehensive literature search was performed in PubMed, Embase, the Cochrane Library, CNKI, and reference lists. Meta-analysis was performed using Stata12.0 software, best corrected visual acuity (BCVA), retinal thickness, and lesion size were evaluated.

Results: Twelve randomized controlled trials spanning from 2010 to 2014 and involving 5,225 patients were included. A significant difference was observed between the intravitreal ranibizumab (IVR) group and the intravitreal bevacizumab group (standard mean difference $=-0.14,95 \%$ confidence interval $[\mathrm{CI}]=-0.23$ to -0.05 ). No significant differences were observed in best corrected VA, retinal thickness, or lesion size between IVR and the intravitreal aflibercept group. Compared to monthly injection, IVR as-needed injections (PRN) can raise VA by 1.97 letters (weighted mean difference $=1.97,95 \% \mathrm{CI}=0.14-3.794$ ). Combination therapy of IVR and photodynamic therapy can significantly raise VA by 2.74 letters when combined with IVR monotherapy (weighted mean difference $=2.74,95 \% \mathrm{CI}=0.26-5.21$ ).

Conclusion: The superiority remains unclear between IVR and intravitreal bevacizumab in the treatment of neovascular AMD. Intravitreal aflibercept dosed every 2 months required fewer injection times, but produced similar efficacy as monthly IVR. IVR PRN could significantly increase VA. Combined with photodynamic therapy, IVR therapy could also increase VA effectively.

Keywords: age-related macular degeneration, VEGF, ranibizumab, bevacizumab, aflibercept, meta-analysis

\section{Introduction}

Age-related macular degeneration (AMD) is the leading cause of vision loss in patients over the age of 65 years in Western populations. ${ }^{1,2}$ It has been estimated that $25 \%$ of Asians will be over 60 years old by $2050,{ }^{3}$ which will constitute a substantial increase in the number of older people over the next few decades. It appears likely that AMD will be a major public health problem representing a significant economic burden.

The wet (neovascular or exudative) form of AMD is responsible for severe visual loss if left untreated. ${ }^{4}$ Vascular endothelial growth factor (VEGF) is widely considered the main growth factor leading to the increased angiogenesis within the eyeballs. ${ }^{5}$ AntiVEGF treatment can prevent further neovascularization from wet AMD. The first breakthrough in anti-VEGF therapy for the treatment of wet AMD treatment was pegaptanib 
(Macugen; Eyetech Inc, Palm Beach Gardens, FL, USA) in 2004. However, visual decline has been found in the AMD patients who were treated with pegaptanib. ${ }^{6,7}$ Bevacizumab (Avastin; Genentech, Inc., South San Francisco, CA, USA/ Hoffman-La Roche Ltd., Basel, Switzerland, first used offlabel in 2005) and Ranibizumab (Lucentis; Genentech, Inc.,/ Hoffman-La Roche Ltd., introduced in 2006) are other two anti-VEGF agents with similar efficacy, presenting a dilemma for clinicians to choose. ${ }^{8}$ Aflibercept (VEGF Trap-eye, Eylea; Regeneron, Tarrytown, NY, USA) is the most recently approved treatment for wet AMD by US Food and Drug Administration in 2011. The binding affinity and long halflife of this agent present the possibility of cost savings and decrease in frequency of use. ${ }^{9}$

The treatment of exudative AMD has evolved considerably in recent years. However, there still remains some effective unanswered questions: 1) which anti-VEGF drug is more effective; 2) which intravitreal ranibizumab (IVR) injection monotherapy is superior to IVR combined with photodynamic therapy (PDT); and 3) which treatment protocol is better. The purpose of this study is to investigate anti-VEGF treatment on neovascular AMD by comparing the efficacy of : 1) IVR with intravitreal bevacizumab (IVB)/intravitreal aflibercept (IVA); 2) ranibizumab monthly injection with as-needed injection (PRN); and 3) IVR monotherapy with combination therapy.

\section{Methods}

\section{Search strategy}

PubMed, Embase, the Cochrane Library, and CNKI from inception until May 2014 were searched independently by two investigators (HS and QYW). The search strategy was based on the combination of medical subject headings and the keywords "age-related macular degeneration", "choroidal neovascularization","anti-VEGF”, "Ranibizumab”, "Bevacizumab", "Aflibercept", and "photodynamic therapy". No restriction to specific languages or years of publication was used. The search strategies for each database were modified to meet the requirements of each database. The citations of related articles were examined for additional publications.

\section{Inclusion and exclusion criteria}

We included randomized controlled trials (RCTs) that compared 1) ranibizumab to bevacizumab; 2) ranibizumab to aflibercept; and 3) ranibizumab monotherapy to the combination with PDT in patients undergoing intravitreal anti-VEGF injection for wet AMD. Studies had to report on one or more of the outcomes of interest with clear documentation. To investigate long-term harm, 1-year follow-up data had to be available.

Studies were excluded if the choroidal neovascular vessel was secondary to some other disease than exudative AMD. Patients previously treated with VEGF inhibitors or who had received systemic anti-VEGF therapy were also excluded. Early studies published as a series of articles from the same institution or author that contained significant overlapping data were excluded. Only the most recently published study containing the most up-to-date data was included.

\section{Data extraction and quality assessment}

Titles and abstracts were reviewed using the above selection criteria by two authors (DX and YHL). Full papers of the relevant studies were obtained for detailed evaluation. Data extraction and quality assessment were conducted using the modified Jadad assessment tool. ${ }^{10}$ Information on the number of participants, comparability of groups, drug dosage, frequency of drug administration, follow-up time, and ascertainment of outcomes (ocular and systemic adverse effects) were abstracted. The primary outcome, best corrected visual acuity (BCVA), and secondary outcomes, retinal thickness and lesion size (LS) of choroidal neovascular vessel with clear reporting were also extracted. Any disagreement was resolved by discussion and consensus.

\section{Statistical analysis}

The meta-analysis was conducted using the Stata software package (version 12.0; StataCorp LP, College Station, TX, USA). For dichotomous variables, the odds ratios (ORs) were measured with 95\% confidence intervals (CIs), while the weighted mean difference (WMD) was measured using the $95 \%$ CIs for continuous variables. The standard mean difference (SMD) was used when all the trials assessed the same outcome in a variety of ways. The level of significance was set at 0.05 , and corresponding 95\% CIs were reported. Statistical heterogeneity among studies was evaluated by the $Q$-statistic and quantified by the $I^{2}$ statistic. Both a fixedeffects model and a random-effects model were used to obtain summary ORs or WMDs. In the absence of heterogeneity between groups, the fixed-effects model was used to provide concordant results. The random-effects model was employed only when the heterogeneity was significant $(P<0.1$ and $I^{2}>50 \%$ ). Studies with higher quality were included in the sensitivity analysis. In order to determine the stability of the combined ORs or WMDs, sensitivity analysis was conducted by changing the random-effects methods to fixed-effects 
methods. Funnel plots and the Egger test were created to visually evaluate for the presence of publication bias.

\section{Results}

\section{Identification and selection of studies}

In total, 1,957 articles were identified initially. After 408 duplicates and 219 unrelated articles were excluded, 1,330 articles were assessed for detailed evaluation. After an independent review, 17 articles were excluded because the duration of follow-up was less than 1 year. Finally, 12 RCTs were included for meta-analysis. The literature search process and exclusion reasons are summarized in Figure 1.

\section{Study characteristics and quality}

Twelve RCTs were eligible based on the inclusion criteria and were selected for this meta-analysis. Six RCTs were conducted in Europe, ${ }^{11-16}$ five in North America, ${ }^{17-21}$ and one in Austria. ${ }^{22}$ Quality assessment showed three trials with a score of $4 .{ }^{14,16,20}$ The baseline characteristics of all RCTs are summarized in Table 1. They spanned from 2010 to 2014 and reported on 5,225 patients. The mean ages of the patients ranged from 73.0 to 80.3 years.

\section{IVR vs IVB}

Five studies were included for this meta-analysis. ${ }^{11,14,18,20,22}$ Figure 2 shows the BCVA of the five RCTs. Effect sizes were homogeneous $\left(I^{2}=18.8 \%, P=0.30\right)$. The pooled analysis showed no significant difference between the IVR group and the IVB group (WMD $=0.47,95 \% \mathrm{CI}=-0.79$ to 1.72 , $P=0.47)$. There was no evidence of heterogeneity $\left(I^{2}=0 \%\right.$, $P=0.85$ ) in the total retinal thickness at fovea (TTF). The pooled analysis did not reveal any significant difference between the two groups (WMD $=-13.16,95 \% \mathrm{CI}=-31.52$ to 5.21, $P=0.16$ ). Four studies provided data on LS. . $^{11,14,18,22}$ The effect sizes were homogeneous $\left(I^{2}=46.6 \%, P=0.13\right)$. A significant difference was observed between the IVR group and the IVB group (SMD $=-0.14,95 \% \mathrm{CI}=-0.23$ to $-0.05, P=0.002$ ).

\section{IVR vs IVA}

Heier et al compared $0.5 \mathrm{mg}$ IVR administered monthly with $2.0 \mathrm{mg}$ IVA every 2 months. ${ }^{21}$ There was no evidence of heterogeneity in BCVA or central retinal thickness (CRT) ( $I^{2}=0 \%, P=0.86 ; I^{2}=0 \%, P=0.94$ ) between the IVR group and the IVA group. The pooled analysis showed no significant

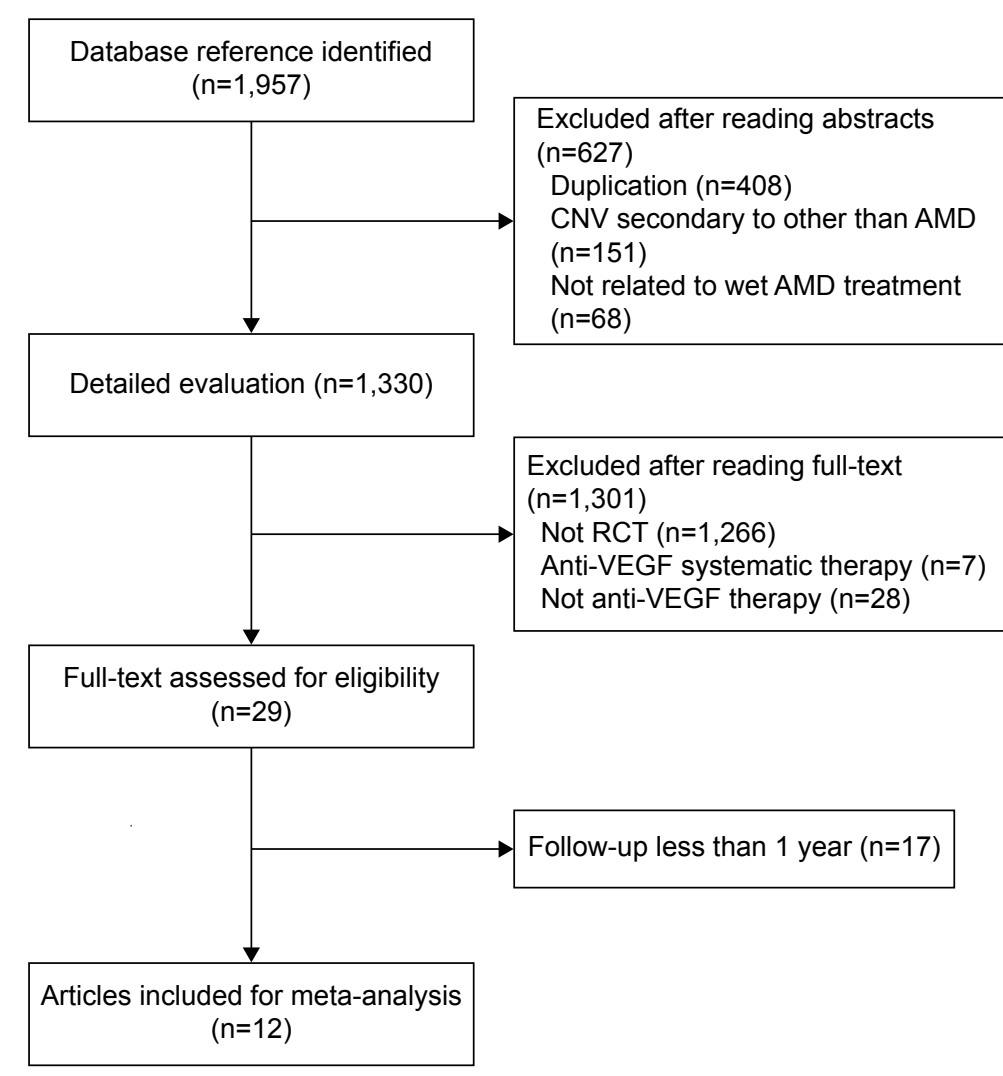

Figure I Search strategy flow diagram regarding anti-VEGF agents for treating wet AMD.

Abbreviations: AMD, age-related macular degeneration; CNV, choroidal neovascularization; RCT, randomized controlled trial; VEGF, vascular endothelial growth factor. 
Table I Characteristics of the included studies for the treatment of AMD

\begin{tabular}{|c|c|c|c|c|c|c|c|c|c|}
\hline Study & Comparison & $\mathbf{n}$ & $\begin{array}{l}\text { Age } \\
\text { (years) }\end{array}$ & Treatment & Duration & Outcomes & $\begin{array}{l}\text { Injection } \\
\text { (time) }\end{array}$ & $P$-value & Jadad score \\
\hline \multirow[t]{2}{*}{ GEFAL"I } & $0.5 \mathrm{mg}$ IVR & 183 & $78.7(7.3)$ & $3+\mathrm{PRN}$ & I year & I) BCVA; 2) central subfield macular & $6.5(2.4)$ & 0.39 & 7 \\
\hline & $1.25 \mathrm{mg}$ IVB & 191 & $79.6(6.9)$ & $3+\mathrm{PRN}$ & & thickness; 3) LS (DA) & $6.8(2.7)$ & & \\
\hline \multirow[t]{2}{*}{ HARBOR $^{17}$} & $0.5 \mathrm{mg}$ IVR & 275 & $78.8(8.4)$ & $q 4 w$ & I year & I) BCVA; 2) CFT; 3) LS (DA) & II.3 (I.8) & l & 7 \\
\hline & $0.5 \mathrm{mg}$ IVR & 275 & $78.5(8.3)$ & $3+\mathrm{PRN}$ & & & $7.7(2.7)$ & & \\
\hline \multirow[t]{2}{*}{ Krebs et $\mathrm{al}^{12}$} & $0.5 \mathrm{mg}$ IVR & 24 & $77.7(8.9)$ & $3+\mathrm{PRN}$ & I year & I) distance acuity; 2) CRT; 3) greatest & $6.6(2.4)$ & 0.074 & 5 \\
\hline & $0.5 \mathrm{mg}$ IVR + PDT & 20 & $80.3(6.3)$ & $3+\mathrm{PRN}$ & & linear diameter of the lesion & $4.7(1.8)$ & & \\
\hline \multirow[t]{2}{*}{ MANTA $^{22}$} & $0.5 \mathrm{mg}$ IVR & 163 & $77.6(8.1)$ & $3+\mathrm{PRN}$ & I year & I) VA; 2) CRT; 3) LS (DA) & $5.8(2.7)$ & 0.26 & 4 \\
\hline & $1.25 \mathrm{mg} \mathrm{IVB}$ & 154 & $76.7(7.8)$ & $3+\mathrm{PRN}$ & & & $6.1(2.8)$ & & \\
\hline \multirow[t]{4}{*}{ CATT $^{18}$} & $0.5 \mathrm{mg}$ IVR & 146 & $79.5(7.4)$ & $q 4 w$ & 2 years & I) VA; 2) TTF; 3) LS (mm²) & $22.4(3.9)$ & 0.01 & 7 \\
\hline & $1.25 \mathrm{mg}$ IVB & 135 & $79.7(7.5)$ & & & & $23.4(2.8)$ & & \\
\hline & $0.5 \mathrm{mg}$ IVR & 287 & $78.3(7.8)$ & $\mathrm{I}+\mathrm{PRN}$ & & & $12.6(6.6)$ & & \\
\hline & $1.25 \mathrm{mg}$ IVB & 270 & $78.9(7.4)$ & & & & I4.| (7.0) & & \\
\hline \multirow[t]{2}{*}{ DENALI' ${ }^{19}$} & $0.5 \mathrm{mg}$ IVR & 112 & $77.2(8.0)$ & $q 4 w$ & I year & I) BCVA; 2) CRT; 3) LS $\left(\mathrm{mm}^{2}\right)$ & 7.6 & I & 5 \\
\hline & $0.5 \mathrm{mg}$ IVR + PDT & 104 & $77.5(8.4)$ & $3+\mathrm{PRN}$ & & & 2.2 & & \\
\hline MONT & $0.5 \mathrm{mg}$ IVR & 133 & $75.5(7.4)$ & $3+\mathrm{PRN}$ & I year & I) BCVA; 2) CRT; 3) LS $\left(\mathrm{mm}^{2}\right)$ & 2.2 & 0.14 & 5 \\
\hline $\mathrm{BLANC}^{13}$ & $0.5 \mathrm{mg}$ IVR + PDT & 122 & $76.8(7.7)$ & $3+P R N$ & & & 1.9 & & \\
\hline \multirow[t]{4}{*}{ IVAN $^{14}$} & $0.5 \mathrm{mg}$ IVR & 314 & $77.8(7.6)$ & $q 4 w$ & I year & I) VA; 2) TTF; 3) (DA) & q4w: 12 & l & 7 \\
\hline & & & & $3+\mathrm{PRN}$ & & & 3+PRN: 7 & & \\
\hline & $1.25 \mathrm{mg}$ IVB & 296 & $77.7(7.2)$ & $q 4 w$ & & & & & \\
\hline & & & & $3+\mathrm{PRN}$ & & & & & \\
\hline Williams & $0.5 \mathrm{mg}$ IVR & 27 & 79.1 & $3+\mathrm{PRN}$ & I year & I) VA; 2) foveal thickness & 6.8 & 0.11 & 4 \\
\hline et $\mathrm{al}^{20}$ & $0.5 \mathrm{mg}$ IVR + PDT & 29 & 79.3 & $\mathrm{I}+\mathrm{PRN}$ & & & 3.0 & & \\
\hline \multirow[t]{2}{*}{ VIEWI'I } & $2.0 \mathrm{mg}$ IVA & 301 & $77.9(8.4)$ & $3 q 8 w$ & 96 weeks & I) BCVA; 2) CRT; 3) LS (mm²) & IVR: 16.5 & l & 5 \\
\hline & $0.5 \mathrm{mg}$ IVR & 304 & $77.8(7.6)$ & $q 4 w$ & & & (3.7) & & \\
\hline \multirow[t]{2}{*}{ VIEW2 $2^{21}$} & $2.0 \mathrm{mg}$ IVA & 296 & $73.8(8.6)$ & $3 q 8 w$ & 96 weeks & & IVA: 11.2 & & \\
\hline & $0.5 \mathrm{mg}$ IVR & 291 & $73.0(9.0)$ & $q 4 w$ & & & $(2.9)$ & & \\
\hline Subramanian & $0.5 \mathrm{mg}$ IVR & 7 & 80 & $3+\mathrm{PRN}$ & I year & I) VA; 2) central macular thickness & 4 & 0.001 & 6 \\
\hline et $\mathrm{al}^{15}$ & $1.25 \mathrm{mg}$ IVB & 15 & 78 & $3+\mathrm{PRN}$ & & & 7 & & \\
\hline Vallance & $0.5 \mathrm{mg}$ IVR & 9 & 1 & $3+\mathrm{PRN}$ & I year & I) BCVA; 2) central macular & 4.3 & 1 & 4 \\
\hline et $\mathrm{al}^{16}$ & $0.5 \mathrm{mg}$ IVR + PDT & 9 & 1 & $3+\mathrm{PRN}$ & & thickness & 4.3 & & \\
\hline
\end{tabular}

Abbreviations: I, not available; BCVA, best corrected visual acuity; CFT, central foveal thickness; CRT, central retinal thickness; DA, disc area; IVA, intravitreal aflibercept; IVB, intravitreal bevacizumab; IVR, intravitreal ranibizumab; LS, lesion size; PDT, photodynamic therapy; PRN, injection as-needed; q4w, every 4 weeks; 3q8w, monthly injection for 3 months then treated as needed; TTF, total retinal thickness at fovea; AMD, age-related macular degeneration; VA, visual acuity.

\section{BCVA of IVR vs IVB on treating wet AMD}

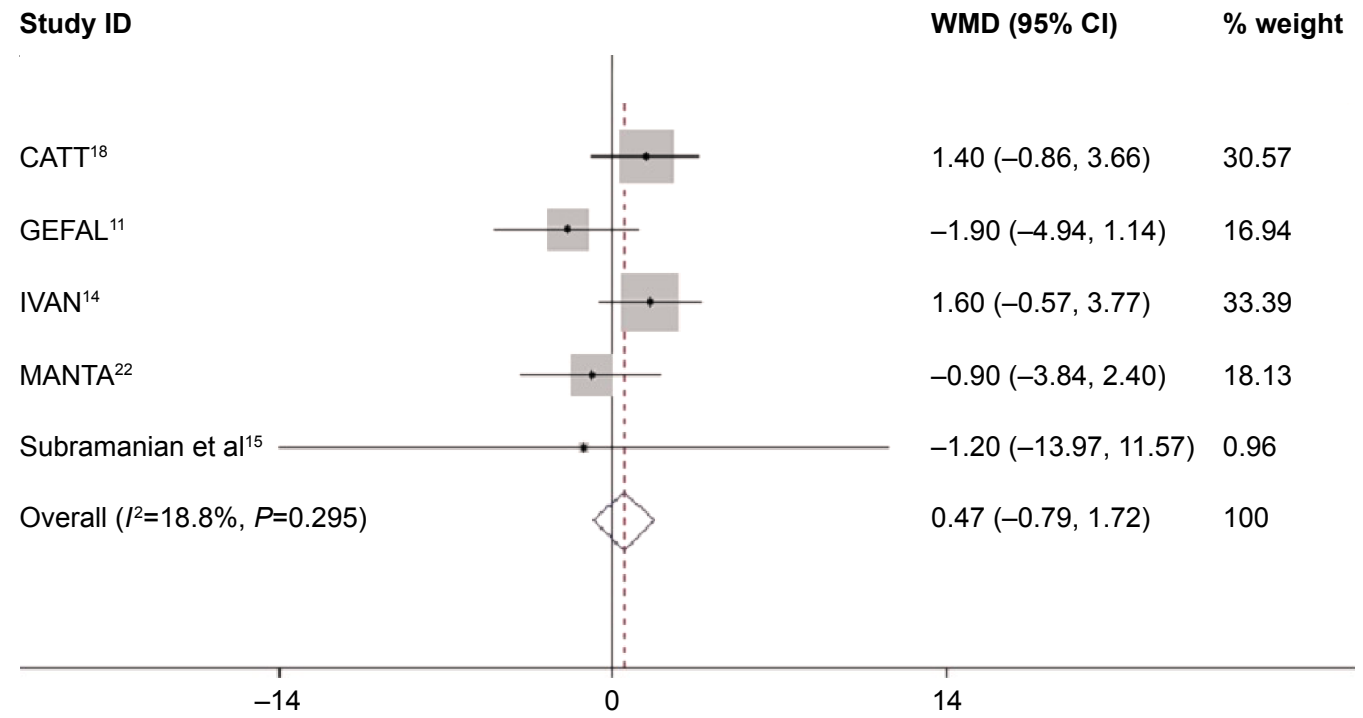

Figure 2 Forest plot of BCVA of IVR vs IVB for treating wet AMD.

Note: No significant difference was observed between the IVR group and the IVB group.

Abbreviations: AMD, age-related macular degeneration; BCVA, best corrected visual acuity; IVB, intravitreal bevacizumab; IVR, intravitreal ranibizumab;WMD, weighted mean difference; $\mathrm{Cl}$, confidence interval. 
difference between the two groups (WMD $=0.36,95 \%$ $\mathrm{CI}=-1.29$ to $2.01, P=0.67 ; \mathrm{WMD}=11.26,95 \% \mathrm{CI}=-1.71$ to 24.24, $P=0.09$ ). A significant difference in LS was observed between the IVR group and the IVA group (WMD $=-0.10$, $95 \% \mathrm{CI}=-1.67$ to $-1.86, P=0.92)$. The random-effects model was used in a meta-analysis of the high heterogeneity of the effect size $\left(I^{2}=85.8 \%, P=0.01\right)$.

\section{IVR monthly vs PRN}

A pooled analysis of the CATT and HARBOR studies showed a significant difference between the two groups (WMD $=1.97,95 \% \mathrm{CI}=0.14-3.794, P=0.04) .{ }^{18,17}$ Compared to monthly injection, PRN treatment can raise visual acuity (VA) by 1.97 letters (Figure 3). No heterogeneity in BCVA $\left(I^{2}=0 \%, P=0.92\right)$ was observed between the two RCTs. We were unable to judge the TTF or LS of the two studies for lack of data. Both studies showed that TTF and LS were reduced after interventions. However, no significant difference was found in the CATT study $(P=0.08, P<0.05) .{ }^{18}$ No conclusion can be drawn from HARBOR for lack of SD and $P$-values. ${ }^{17}$

\section{IVR monotherapy vs IVR combined with PDT}

Five studies assessed the efficacy of monotherapy and combined therapy. ${ }^{12,13,16,19,20}$ No heterogeneity in BCVA and LS was observed among the studies $\left(I^{2}=0 \%, P=0.72 ; I^{2}=0 \%\right.$, $P=0.36)$. Combined therapy significantly raised VA by 2.74 letters combined with monotherapy $(\mathrm{WMD}=2.74,95 \%$ $\mathrm{CI}=0.26-5.21, P=0.03$ ) (Figure 4). No significant difference could be observed in $\mathrm{LS}$ (WMD $=0.05,95 \% \mathrm{CI}=-0.05$ to $0.14, P=0.35)$. High heterogeneity in CRT was observed in the included studies $\left(I^{2}=72.8 \%, P=0.03\right)$. A pooled analysis on random effect showed no significant difference among the groups ( $\mathrm{WMD}=4.66,95 \% \mathrm{CI}=-30.37$ to $39.68, P=0.79$ ). Table 2 summarized the overall effect and heterogeneity of the pooled studies. Vallance et al found that the PDT group gained a mean of 2.2 letters and the IVR group gained a mean of 4.4 letters at 1 year $(P=0.47) .{ }^{16}$ The mean CRT was reduced by $138 \mu \mathrm{m}$ in the PDT group and by $103 \mu \mathrm{m}$ in the $\operatorname{IVR}$ group $(P=0.57)$.

\section{Severe local or systemic complications}

Endophthalmitis was reported after anti-VEGF injections with incidence rates less than or equal to $1.8 \%$ in the IVR group (2/111) in DENALI. ${ }^{19}$ The DENALI trial reported 20 cases of cataract in the group of patients receiving IVR group (8/111) and the IVR + PDT group (12/210). The CATT study reported the deaths of $32(5.3 \%)$ IVR patients $(32 / 599)$ and $36(6.1 \%)$ IVB patients $(36 / 586) .{ }^{18}$ There were three trials reporting no adverse events. ${ }^{12,15,16}$ Detailed frequencies of complications are provided in Table 3.

\section{Sensitivity analyses and publication bias}

Sensitivity analysis was performed to assess the influence of each individual study on the pooled WMD by the sequential removal of individual studies. The results suggested that no individual study dominantly affected the overall WMD dominantly. These sensitivity analyses indicated that our conclusions were generally robust. Unfortunately, no funnel

\section{BCVA of $0.5 \mathrm{mg}$ IVR monthly vs PRN}

\begin{tabular}{|c|c|c|}
\hline Study ID & WMD $(95 \% \mathrm{Cl})$ & $\%$ weight \\
\hline CATT $^{18}$ & $2.10(-1.12,5.32)$ & 32.32 \\
\hline $\mathrm{HARBOR}^{17}$ & $1.90(-0.32,4.12)$ & 67.68 \\
\hline Overall $\left(I^{2}=0.0 \%, P=0.920\right)$ & $1.96(0.14,3.79)$ & 100 \\
\hline
\end{tabular}

Figure 3 Forest plot of BCVA of monthly IVR vs PRN for treating wet AMD.

Notes: A significant difference was shown between the two groups. Compared to monthly injection, PRN treatment can raise VA by I.97 letters (WMD =1.97, $95 \%$ $\mathrm{Cl}=0.14-3.794, P=0.04)$.

Abbreviations: AMD, age-related macular degeneration; BCVA, best corrected visual acuity; $\mathrm{Cl}$, confidence interval; IVR, intravitreal ranibizumab; PRN, injection as-needed; WMD, weighted mean difference; VA, visual acuity. 


\section{BCVA of IVR monotherapy vs IVR + PDT}

\begin{tabular}{|c|c|c|}
\hline Study ID & WMD $(95 \% \mathrm{Cl})$ & $\%$ weight \\
\hline DENALII9 & $3.30(-0.23,6.83)$ & 49.29 \\
\hline Krebs et al ${ }^{12}$ & $-2.02(-16.42,12.38)$ & 2.96 \\
\hline MONT BLANC ${ }^{13}$ & $1.90(-1.88,5.68)$ & 42.90 \\
\hline Williams et $\mathrm{al}^{20}$ & $-7.30(-3.95,18.55)$ & 4.85 \\
\hline Overall $\left(I^{2}=0.0 \%, P=0.720\right)$ & $2.74(0.26,5.21)$ & 100 \\
\hline
\end{tabular}

Figure 4 Forest plot of BCVA of IVR monotherapy vs IVR+PDT for treating wet AMD.

Notes: A significant difference was shown between the two groups. Compared to monotherapy, the combination therapy can raise VA by 2.74 letters (WMD $=2.74,95 \%$ $\mathrm{Cl}=0.26-5.21, P=0.03)$.

Abbreviations: AMD, age-related macular degeneration; BCVA, best corrected visual acuity; Cl, confidence interval; IVR, intravitreal ranibizumab; PDT, photodynamic therapy; WMD, weighted mean difference; VA, visual acuity.

plot could be drawn for the meta-analysis because there were fewer than ten remaining studies.

\section{Discussion}

This meta-analysis included 12 RCTs of small or medium sample size. The quality of most of the evidence in this systematic review was moderate. Clinical evidence has been accumulating since intravitreal anti-VEGF injection was first applied in wet AMD patients. Bevacizumab, an off-label drug, showed promising results in the published series for treating neovascular AMD. ${ }^{23-30}$ Because it was significantly cheaper than ranibizumab, bevacizumab was supplied to a greater number of patients. Ranibizumab, a drug approved by China Food and Drug Administration for treating wet AMD, has been shown in several large, double-blinded, multicenter RCTs to produce mean BCVA improvement in wet AMD patients. ${ }^{31-34}$ Previous meta-analysis observed similar effects on BCVA and TTF, which were consistent with our results. ${ }^{35,36}$ However, our meta-analysis found that compared to bevacizumab, ranibizumab decreased LS for the control of wet AMD. SMD was chosen in our meta-analysis because of different units (disc area and $\mathrm{mm}^{2}$ ) in the included trials. Moreover, significant differences in injection time were found in two trials. ${ }^{15,18}$ There were only two to five trials for

Table 2 Summary of overall effect and heterogeneity of pooled studies

\begin{tabular}{|c|c|c|c|c|c|c|}
\hline \multirow[t]{2}{*}{ Comparisons } & \multirow[t]{2}{*}{$\mathbf{n}$} & \multirow[t]{2}{*}{ Outcomes } & \multicolumn{2}{|l|}{ Overall effect } & \multicolumn{2}{|c|}{ Study heterogeneity } \\
\hline & & & WMD (95\% Cl) & $P$-value & $1^{2}, \%$ & $P$-value \\
\hline \multirow[t]{3}{*}{ IVR vs IVB } & 2,011 & BCVA & $0.47(-0.79$ to 1.72$)$ & 0.47 & 18.8 & 0.30 \\
\hline & 1,199 & TTF & $-13.16(-31.52$ to 5.21$)$ & 0.16 & 0 & 0.85 \\
\hline & $\mathrm{I}, 90 \mathrm{I}$ & LS & $-0.14(-0.23 \text { to }-0.05)^{*}$ & 0.002 & 46.6 & 0.13 \\
\hline \multirow[t]{3}{*}{ IVR vs IVA } & 1,192 & BCVA & $0.36(-1.29$ to 2.01$)$ & 0.67 & 0 & 0.86 \\
\hline & $\mathrm{I}, 192$ & CRT & II.26 (-I.7I to 24.24$)$ & 0.09 & 0 & 0.94 \\
\hline & 1,192 & LS & $-0.10(-1.67$ to -1.86$)$ & 0.92 & 85.8 & 0.01 \\
\hline IVR monthly vs PRN & 948 & BCVA & $1.97(0.14-3.794)$ & 0.04 & 0 & 0.92 \\
\hline \multirow[t]{3}{*}{ IVR vs IVR + PDT } & 668 & BCVA & $2.74(0.26-5.2 I)$ & 0.03 & 0 & 0.72 \\
\hline & 612 & CRT & $4.66(-30.37$ to 39.68$)$ & 0.79 & 72.8 & 0.03 \\
\hline & 571 & LS & $0.05(-0.05$ to 0.14$)$ & 0.35 & 0 & 0.36 \\
\hline
\end{tabular}

Note: *The overall effect was SMD.

Abbreviations: BCVA, best corrected visual acuity; CRT, central retinal thickness; IVA, intravitreal aflibercept; IVB, intravitreal bevacizumab; IVR, intravitreal ranibizumab; LS, lesion size; PDT, photodynamic therapy; PRN, injection as needed; SMD, standard mean difference; TTF, total retinal thickness at fovea; Cl, confidence interval; WMD, weighted mean difference. 
Table 3 Frequency of complications of included trials

\begin{tabular}{|c|c|c|c|c|c|c|}
\hline Study & Comparisons & Death & Hypertension & & Retinal hemorrhage & Cataract \\
\hline \multirow[t]{2}{*}{ GEFAL"I } & IVR & $3(1.3 \%)$ & $2(0.8 \%)$ & 1 & 2 & 1 \\
\hline & IVB & $2(0.8 \%)$ & I (0.4\%) & 0 & 1 & I \\
\hline \multirow[t]{2}{*}{$\mathrm{HARBOR}^{17}$} & IVR q4w & $8(2.9 \%)$ & 0 & $2(0.7 \%)$ & 0 & I \\
\hline & IVR PRN & $4(1.5 \%)$ & I (0.4\%) & 0 & I (0.4\%) & I \\
\hline \multirow[t]{2}{*}{ Krebs et a $\left.\right|^{12}$} & IVR & 0 & 0 & 0 & 0 & 0 \\
\hline & IVR + PDT & 0 & 0 & 0 & 0 & 0 \\
\hline \multirow[t]{2}{*}{ MANTA $^{22}$} & IVR & $2(1.2 \%)$ & l & 0 & 0 & 0 \\
\hline & IVB & $3(1.9 \%)$ & l & 0 & 0 & 0 \\
\hline \multirow[t]{2}{*}{ CATT $^{18}$} & IVR & $32(5.3 \%)$ & $3(0.5 \%)$ & $4(0.7 \%)$ & l & l \\
\hline & IVB & $36(6.1 \%)$ & $4(0.7 \%)$ & 7 (I.2\%) & l & l \\
\hline \multirow{2}{*}{ DENALI ${ }^{19}$} & IVR & $5(4.5 \%)$ & I & $2(1.8 \%)$ & $9(8.1 \%)$ & $8(7.2 \%)$ \\
\hline & IVR + PDT & $8(3.8 \%)$ & l & I (0.05\%) & $16(7.6 \%)$ & $12(5.7 \%)$ \\
\hline \multirow[t]{2}{*}{ MONT BLANC'13 } & IVR & I $(0.08 \%)$ & $6(4.5 \%)$ & 0 & $4(3.0 \%)$ & I \\
\hline & IVR + PDT & 0 & $10(8.2 \%)$ & 0 & $6(4.9 \%)$ & I \\
\hline \multirow[t]{2}{*}{ IVAN' $^{14}$} & IVR & $6(1.9 \%)$ & $6(1.9 \%)$ & I & l & I \\
\hline & IVB & $5(1.7 \%)$ & $5(1.7 \%)$ & l & I & I \\
\hline \multirow[t]{2}{*}{ Williams et $\mathrm{al}^{20}$} & IVR & 1 & I & I & I & l \\
\hline & IVR + PDT & l & l & l & l & I \\
\hline \multirow[t]{2}{*}{ VIEWI II } & IVA 3q8w & $4(1.3 \%)$ & $31(10.2 \%)$ & 0 & $2(0.7 \%)$ & I \\
\hline & IVR q4w & I (0.3\%) & $29(9.5 \%)$ & $3(1.0 \%)$ & $2(0.7 \%)$ & I \\
\hline \multirow[t]{2}{*}{ VIEW $2^{21}$} & IVA 3q8w & I (0.3\%) & $28(9.1 \%)$ & 0 & I (0.3\%) & I \\
\hline & IVR q4w & I (0.3\%) & $29(10 \%)$ & 0 & I (0.3\%) & I \\
\hline \multirow[t]{2}{*}{ Subramanian et $\mathrm{al}^{15}$} & IVR & 0 & 0 & 0 & 0 & 0 \\
\hline & IVB & 0 & 0 & 0 & 0 & 0 \\
\hline \multirow[t]{2}{*}{ Vallance et $\mathrm{al}^{16}$} & IVR & 0 & 0 & 0 & 0 & 0 \\
\hline & IVR + PDT & 0 & 0 & 0 & 0 & 0 \\
\hline
\end{tabular}

Abbreviations: IVA, intravitreal aflibercept; IVB, intravitreal bevacizumab; IVR, intravitreal ranibizumab; q4w, every 4 weeks; 3q8w, monthly injection for 3 months then treated as needed; PDT, photodynamic therapy; PRN, injection as-needed.

different drug type in each comparison, which made it impossible to investigate the differences among drugs in indirect subgroup comparisons. In summary, it can be concluded that IVR and IVB may have comparable visual benefits for patients suffering from neovascular AMD.

Aflibercept is another intravitreal agent that clearly provides vision benefits in the treatment of neovascular AMD. ${ }^{37}$ Current evidence from this meta-analysis did not reveal much difference in the terms of mean vision change, retinal thickness, and LS between the IVR $\mathrm{q} 4 \mathrm{w}$ and IVA $\mathrm{q} 8 \mathrm{w}$ groups. The meta-analysis of the VIEW study with $52 \mathrm{w}$ results demonstrated that IVA dosed every 2 months after three initial monthly doses produced similar efficacy as monthly IVR. ${ }^{21}$ Furthermore, patients in the IVA q8w group achieved visual and anatomical improvements similar to the IVR $\mathrm{q} 4 \mathrm{w}$ group with a mean of five fewer injections over 96w. ${ }^{38}$ Unfortunately, we cannot perform meta-analysis on VIEW (96w) for lack of SD and $P$-values.

The previous clinical evidence indicated that IVR with three consecutive monthly injections is optimal, providing the greatest VA gain. ${ }^{31,32}$ In 2010, the small, prospective, single-center, nonrandomized PrONTO study assessed three consecutive monthly injections followed by optical coherence tomography-guided variable dosing (PRN intervals) ${ }^{34}$ The PRN strategy suggested that flexible optical coherence tomography-guided treatment could sustain visual gain with fewer injections. Clinical recommendations (level III evidence) indicated that the flexible strategy with monthly monitoring was more feasible when a monthly regimen was impossible. The benefits could be less than with monthly treatment. However, the pooled analysis of VA gain showed that compared to IVR monthly injection, the PRN strategy provided a 1.97 letters increase.

IVR could provide further improvement or reduce the necessary reinjection frequency when combined with PDT. The result of the MONT BLANC study showed that PDT in combination with ranibizumab was effective and could achieve BCVA in AMD patients. ${ }^{13}$ Our meta-analysis with four RCTs indicated that the combination therapy could improve BCVA by 2.74 letters than IVR monotherapy effectively. Retinal thickness and LS did not show any significant difference between the two groups because of the unbalanced baseline and different measurement methods. 
Safety was overall good in the included RCTs. The adverse events of anti-VEGF drugs tended mildly toward moderate, short-lived events. Some serious and rare adverse events, for example, death or endophthalmitis, could not be properly evaluated in the RCTs because they were relatively short and small events for this meta-analysis. Furthermore, studies that excluded patients with uncontrolled hypertension or previous cardiovascular patients might limit generalizability to the AMD population. A specific safety review that includes nonrandomized comparative studies is needed. The lack of clarity in reporting adverse events could be a limitation for systematic reviews.

The limitations of this meta-analysis were as follows. First, the indexes of retinal thickness, CRT, and TTF, were not perfectly matched in each trial, which may influence the outcomes of interest. Second, some parameters of interest demonstrated a large degree of heterogeneity. The heterogeneity in the decrease in retinal thickness and lesion area may be influenced by patients baseline characteristics and different methods of measurement. Third, the heterogeneity of patients population and study location of the included studies should be considered. One- or two-year data, which were insufficiently represented in this review, are necessary because AMD is a chronic condition, and therefore, a longterm perspective is needed.

\section{Conclusion}

Twelve RCTs were analyzed in this meta-analysis, which evaluated the effectiveness of intravitreal anti-VEGF in the treatment of neovascular AMD. The superiority remains unclear between IVR and IVB in the treatment of neovascular AMD. IVA dosed every 2 months required fewer injection times, but produced similar efficacy as monthly IVR. The dosing method could be either monthly or PRN, and IVR PRN could significantly increase VA. Combined with PDT, IVR therapy could increase VA effectively. Further studies with long-term observation are required to elucidate the ultimate prognosis of neovascular AMD.

\section{Acknowledgments}

This work was supported in whole or in part, by National Nature Science Foundation Project (81470648) and The New Excellence Project of Shanghai Health Bureau (XYQ2011067).

\section{Disclosure}

The authors report no conflicts of interest in this work.

\section{References}

1. Pascolini D, Mariotti SP, Pokharel GP, et al. 2002 global update of available data on visual impairment: a compilation of population-based prevalence studies. Ophthalmic Epidemiol. 2004;11(2):67-115.

2. Friedman DS, O'Colmain BJ, Mufioz B, et al. Eye Diseases Prevalence Research Group: prevalence of age-related macular degeneration in the United States. Arch Ophthalmol. 2004;122(4):564-572.

3. Kawasaki R, Yasuda M, Song SJ, et al. The prevalence of age-related macular degeneration in Asians- a systematic review and meta-analysis. Ophthalmology. 2010;117(5):921-927.

4. Wong T, Chakravarthy U, Klein R, et al. The natural history and prognosis of neovascular age-related macular degeneration- a systematic review of the literature and meta-analysis. Ophthalmology. 2008;115(1): $116-126$.

5. Thomas M, Mousa SS, Mousa SA. Comparative effectiveness of aflibercept for the treatment of patients with neovascular age-related macular degeneration. Clin Ophthalmol. 2013;7:495-501.

6. Emerson MV, Lauer AK. Current and emerging therapies for the treatment of age-related macular degeneration. Clin Ophthalmol. 2008; 2(2):377-388

7. Gragoudas ES, Adamis AP, Cunningham ET Jr, Feinsod M, Guyer DR. Pegaptanib for neovascular age-related macular degeneration. $N$ Engl J Med. 2004;351(27):2805-2816.

8. Cruess AF, Berger A, Colleaux K, et al. Canadian expert consensus: optimal treatment of neovascular age-related macular degeneration. Can J Ophthalmol. 2012;47(3):227-235.

9. Browning DJ, Kaiser PK, Rosenfeld PJ, Stewart MW. Aflibercept for age-related macular degeneration: a game-changer or quiet addition? Am J Ophthalmol. 2012;154(2):222-226.

10. Jadad AR, Moore RA, Carroll D, et al. Assessing the quality of reports of randomized clinical trials: is blinding necessary? Control Clin Trial. 1996;17(1):1-12.

11. Kodjikian L, Souied EH, Mimoun G, et al. Ranibizumab versus Bevacizumab for neovascular age-related macular degeneration: results from the GEFAL noninferiority ranibizumab trial. Ophthalmology. 2013;120(11):2300-2309

12. Krebs I, Vecsei Marlovits V, Bodenstorfer J, et al. Comparison of Ranibizumab monotherapy versus combination of Ranibizumab with photodynamic therapy with neovascular age-related macular degeneration. Acta Ophthalmologica. 2013;91(3):e178-e183.

13. Larsen M, Schmidt-Erfurth U, Lanzetta P, et al. Verteporfin plus ranibizumab for choroidal neovascularization in age-related macular degeneration: twelve-month MONT BLANC study results. Ophthalmology. 2012; 119(5):992-1000.

14. Chakravarthy U, Harding SP, Rogers CA, et al. Ranibizumab versus bevacizumab to treat neovascular age-related macular degeneration: oneyear findings from the IVAN randomized trial. Ophthalmology. 2012; 119(7):1399-1411

15. Subramanian ML, Abedi G, Ness S, et al. Bevacizumab vs ranibizumab for age-related macular degeneration: 1-year outcomes of a prospective, double-masked randomised clinical trial. Eye (Lond). 2010;24(11):1708-1715.

16. Vallance JH, Johnson B, Majid MA, Banerjee S, Mandal K, Bailey CC. A randomised prospective double-masked exploratory study comparing combination photodynamic treatment and intravitreal ranibizumab monotherapy in the treatment of neovascular age-related macular degeneration. Eye (Lond). 2010;24(10):1561-1567.

17. Busbee BG, Ho AC, Brown DM, et al; HARBOR Study Group. Twelve-month efficacy and safety of $0.5 \mathrm{mg}$ or $2.0 \mathrm{mg}$ ranibizumab in patients with subfoveal neovascular age-related macular degeneration. Ophthalmology. 2013;120(5):1046-1056.

18. Martin DF, Maguire MG, Fine SL, et al; Comparison of Age-related Macular Degeneration Treatments Trials (CATT) Research Group. Ranibizumab and bevacizumab for treatment of neovascular age-related macular degeneration: two-year results. Ophthalmology. 2012;119(7): 1388-1398 
19. Kaiser PK, Boyer DS, Cruess AF, Slakter JS, Pilz S, Weisberger A. Verteporfin plus ranibizumab for choroidal neovascularization in agerelated macular degeneration: twelve-month results of the DENALI study. Ophthalmology. 2012;119(5):1001-1010.

20. Williams PD, Callanan D, Solley W, Avery RL, Piramici DJ, Aaberg T. A prospective pilot study comparing combined intravitreal ranibizumab and half-influence photodynamic therapy with ranibizumab in the treatment of neovascular age-related macular degeneration. Clin Ophthalmol. 2012;6:1529-1525.

21. Heier JS, Brown DM, Chong V, et al; VIEW 1 and VIEW 2 Study Groups. Intravitreal aflibercept (VEGF trap-eye) in wet age-related macular degeneration. Ophthalmology. 2012;119(12):2537-2548.

22. Krebs I, Schmetterer L, Boltz A, et al; MANTA Research Group. A randomised double-masked trial comparing the visual outcome after treatment with ranibizumab or bevacizumab in patients with neovascular age-related macular degeneration. Br J Ophthalmol. 2013;97(3): 266-271.

23. Spaide RF, Laud K, Fine HF, et al. Intravitreal bevacizumab treatment of choroidal neovascularization secondary to age-related macular degeneration. Retina. 2006;26(4):383-390.

24. Bashshur ZF, Haddad ZA, Schakal A, Jaafar RF, Saab M, Noureddin BN. Intravitreal bevacizumab for treatment of neovascular age-related macular degeneration: a one-year prospective study. Am J Ophthalmol. 2008;145(2):249-256.

25. Sacu S, Michels S, Prager F, et al. Randomised clinical trial of intravitreal Avastin vs photodynamic therapy and intravitreal triamcinolone: long-term results. Eye (Lond). 2009;23(12):2223-2227.

26. Rich RM, Rosenfeld PJ, Puliafito CA, et al. Short-term safety and efficacy of intravitreal bevacizumab (Avastin) for neovascular age-related macular degeneration. Retina. 2006;26(5):495-511.

27. Tufail A, Patel PJ, Egan C, et al. Bevacizumab for neovascular age related macular degeneration (ABC Trial): multicentre randomised double masked study. BMJ. 2010;340:c2459.

28. Bashshur ZF, Schakal A, Hamam RN, El Haibi CP, Jaafar RF, Noureddin BN. Intravitreal bevacizumab vs verteporfin photodynamic therapy for neovascular age-related macular degeneration. Arch Ophthalmol. 2009;125(10):1357-1361.
29. Ghazi NG, Knape RM, Kirk TQ, Tiedeman JS, Conway BP. Intravitreal bevacizumab (avastin) treatment of retinal angiomatous proliferation. Retina. 2008;28(5):689-695.

30. Goff MJ, Johnson RN, McDonald HR, Ai E, Jumper JM, Fu A. Intravitreal bevacizumab for previously treated choroidal neovascularization from age-related macular degeneration. Retina. 2007;27(4): $432-438$.

31. Rosenfeld PJ, Brown DM, Heier JS, et al. Ranibizumab for neovascular age-related macular degeneration. $N$ Engl J Med. 2006;355(14): 1419-1431.

32. Brown DM, Michels M, Kaiser PK, et al. Ranibizumab versus verteporfin photodynamic therapy for neovascular age-related macular degeneration: two-year results of the ANCHOR study. Ophthalmology. 2009;116(1):57-65.

33. Kaiser PK, Blodi BA, Shapiro H, Acharya NR. Angiographic and optical coherence tomographic results of the MARINA study of ranibizumab in neovascular age-related macular degeneration. Ophthalmology. 2007;114(10):1868-1875.

34. Mitchell P, Korobelnik JF, Lanzetta P, et al. Ranibizumab (Lucentis) in neovascular age-related macular degeneration: evidence from clinical trials. Br J Ophthalmol. 2010;94(1):2-13.

35. Zhang XY, Guo XF, Zhang SD, et al. Comparison of bevacizumab and ranibizumab in age-related macular degeneration: a systematic review and meta-analysis. Int J Ophthalmol. 2014;7(2):355-364

36. Solom SD, Lindsley K, Vedula SS, Krzystolik MG, Hawkins BS. Antivascular endothelial growth factor for neovascular age-related macular degeneration. Cochrane Database Syst Rev. 2014;8:CD005139.

37. Stewart MW. Clinical and differential utility of VEGF inhibitors in wet age-related macular degeneration: focus on aflibercept. Clin Ophthalmol. 2012;6:1175-1186.

38. Schmidt-Erfurth U, Kaiser PK, Korobelnik JF, et al. Intravitreal aflibercept injection for neovascular age-related macular degeneration: ninety-six week results of the VIEW studies. Ophthalmology. 2014; 121(1):193-201.
Drug Design, Development and Therapy

\section{Publish your work in this journal}

Drug Design, Development and Therapy is an international, peerreviewed open-access journal that spans the spectrum of drug design and development through to clinical applications. Clinical outcomes, patient safety, and programs for the development and effective, safe, and sustained use of medicines are a feature of the journal, which

\section{Dovepress}

has also been accepted for indexing on PubMed Central. The manuscript management system is completely online and includes a very quick and fair peer-review system, which is all easy to use. Visit http://www.dovepress.com/testimonials.php to read real quotes from published authors. 